\title{
Transduction of Penicillinase Production and Other Antibiotic-resistance Markers in Staphylococcus epidermidis
}

\author{
By S. M. POSTON AND T. J. PALMER \\ Department of Microbiology, Guy's Hospital Medical School, London SEI $9 R T$
}

(Received I2 April 1977; revised I August 1977)

Transduction of resistance from a multiply antibiotic-resistant strain of Staphylococcus epidermidis sub-group II was studied using the typing phage 108. The effect of increasing doses of ultraviolet radiation on the transducing phage was used to indicate the chromosomal or plasmid nature of the genes. Tetracycline and chloramphenicol resistance behaved as plasmid genes and streptomycin resistance as a chromosomal marker. It was also possible to transduce penicillin resistance $(\mathrm{Pc})$ due to penicillinase production $\left(\mathrm{bla}^{+}\right)$using a low level of benzylpenicillin $\left(0.03 \mu \mathrm{g} \mathrm{ml}^{-1}\right)$ for recovery. Approximately $10^{-5}$ transductant colonies per phage input were obtained and ultraviolet kinetics indicated that $\mathrm{Pc}$ was plasmid carried. Pc transductants fell into two categories. In one group Pc was stable as in the donor strain and transductants had the same phage sensitivity as the recipient. In the other, Pc was unstable at $37^{\circ} \mathrm{C}$ and the instability was enhanced by growth at approximately $43.5^{\circ} \mathrm{C}$; these transductants also gained genes for restriction and modification of certain phages. Transductants that subsequently lost $b l a^{+}$also lost the restriction and modification characters.

\section{INTRODUCTION}

Staphylococcus epidermidis is a common inhabitant of the human skin (Noble, 1969) and strains of this group are often resistant to one or more antibacterial agents (Corse \& Williams, 1968). The genetic determinants for certain types of drug resistance have been transferred by transduction including the genes responsible for resistances to novobiocin, streptomycin and erythromycin (Yu \& Baldwin, 1971). A plasmid location was established for the determinants of resistance to tetracycline (Minshew \& Rosenblum, 1972, 1973) and to chloramphenicol, tetracycline and neomycin (Rosendorf \& Kayser, 1974) based on the reversion of organisms to sensitivity and the effect of ultraviolet (u.v.) irradiation of the transducing phage on the frequency of transduction. In the latter study, the determinant for streptomycin resistance was chromosomal using these criteria. Several attempts to transfer penicillin resistance due to penicillinase production have been unsuccessful (Yu \& Baldwin, I971; Rosendorf \& Kayser, 1974) but recently Nazar, Heczko \& Pulverer (1977), using a group of atypical multi-resistant strains (BV) of $S$. epidermidis in which loss of penicillinase was associated with loss of the ability to ferment mannitol and ribose aerobically (Schaefler, 1972), have shown cotransduction of these three markers in these strains.

This study was undertaken to investigate the genetic nature of penicillin resistance and of other antibiotic-resistance determinants in a multi-resistant strain of $S$. epidermidis. 


\section{METHODS}

Bacterial strains and phages. Strains were isolated from clinical specimens and staphylococci were recognized as belonging to $S$. epidermidis sub-group II (Baird-Parker, 1963) which is biotype I (Baird-Parker, 1974). The tests used for identification were coagulase, phosphatase and acetoin production, acid production from lactose, arabinose and maltose, and aerobic or anaerobic breakdown (O-F) of glucose and mannitol. Methods were based on those of Baird-Parker (1966), Corse \& Williams (1968) for coagulase production and Chalmers (1972) for the O-F test.

Strain BSIO was used as the donor in transduction experiments and ASI5 as the recipient. Strain BSIO produced penicillinase $\left(b_{l a}\right)$ and was resistant to penicillin $(\mathrm{Pc})$, tetracycline $(\mathrm{Tc})$, chloramphenicol $(\mathrm{Cm})$, streptomycin $(\mathrm{Sm})$ and methicillin, and to mercury $(\mathrm{Hg})$ and cadmium $(\mathrm{Cd})$ ions. Strain AS I 5 was sensitive to all of these agents and did not produce penicillinase (bla $\left.{ }^{-}\right)$but was resistant to kanamycin $(\mathrm{Km})$ and neomycin. Strain 1833 , used as a source of phage for strain identification, was provided by Ms B. A. Dean.

Phages 82 and 108 and their respective propagating strains PS87 and PS407 were kindly provided by Dr C. P. A. van Boven. Strains BSIO and ASI 5 were both sensitive to phage 108 although the titre on BSIO was IO-fold lower and the plaques were smaller than on ASI5. Phage I08 was used as the transducing phage in all experiments after three single-plaque isolations and final propagation by the soft agar layer method (Adams, 1959) on the donor strain Bsio. The phage lysate obtained from propagation of the third purified plaque was used as a stock for the propagation of subsequent batches of phage for transduction experiments. When this was exhausted, a further single plaque propagation was made. Harvested phage was filtered through sintered glass (Gallenkamp 5/3) and stored at $4{ }^{\circ} \mathrm{C}$. Phage 108 was assayed on strain ASI 5 on which it gave a very similar titre to that obtained on PS407.

Media. Nutrient broth was Oxoid nutrient broth no. 2. Nutrient agar was nutrient broth solidified with $\mathbf{I} \cdot 2 \%(\mathrm{w} / \mathrm{v})$ Davis agar. Brain heart infusion broth (BHI broth, Oxoid) was used solidified with $\mathrm{I} \cdot 2 \%(\mathrm{w} / \mathrm{v})$ Davis agar for BHI agar. CY and $0.03 \mathrm{CY}$ were the media of Novick (1963). CY agar with $0.2 \%$ (w/v) starch was used for recovery of penicillinase-negative colonies. Calcium chloride $\left(\mathrm{CaCl}_{2} .2 \mathrm{H}_{2} \mathrm{O}, 400 \mu \mathrm{g} \mathrm{ml}^{-1}\right)$ was added to all media for phage propagation, assay and adsorption.

Sensitivity tests. Discs (Mast or Oxoid) containing the drugs (concentration in $\mu \mathrm{g}$ ) chloramphenicol (IO), tetracycline (IO), streptomycin (I0), penicillin (I) and kanamycin (5 or 30), were applied to the surface of sensitivity test agar (DST, Oxoid) plates inoculated either from an overnight nutrient broth culture, to give confluent growth, or from colonies suspended in quarter-strength Ringers solution, to give semiconfluent growth, and incubated at $37^{\circ} \mathrm{C}$. Methicillin $(10 \mu \mathrm{g})$ resistance was tested on nutrient agar plates at $30^{\circ} \mathrm{C}$ using an inoculum to give confluent growth. Metal-ion sensitivity was tested on $0.3 \mathrm{CY}$ agar without

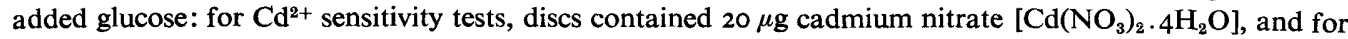
$\mathrm{Hg}^{2+}$ sensitivity tests, either $6 \cdot 7 \mu \mathrm{g}$ mercuric nitrate $\left[\mathrm{Hg}\left(\mathrm{NO}_{3}\right)_{2} \cdot \mathrm{H}_{2} \mathrm{O}\right]$ or $\mathrm{I} \cdot 3 \mu \mathrm{g}$ phenylmercuric nitrate.

Transduction procedure. Based on the method used for $S$. aureus (Poston, I966), the recipient strain was grown in nutrient broth to about $3 \times 10^{8}$ colony forming units (c.f.u.) $\mathrm{ml}^{-1}$, estimated as an extinction of 0.4 for a $1 \cdot 5 \mathrm{~cm}$ light path at $540 \mathrm{~nm}$ (Bausch \& Lomb Spectronic 20). The bacterial culture was concentrated twofold, then mixed with an equal volume of the phage suspension, to give input ratios of 0.06 to $1 \cdot 0$, and incubated for $30 \mathrm{~min}$ at $37^{\circ} \mathrm{C}$. Four volumes of BHI broth containing 0.01 M-tri-sodium citrate was added, the mixture was centrifuged and the deposit was resuspended in BHI broth to the original volume of phage suspension used in the mixture. For recovery of transductants, the resuspended bacteria were plated directly on to chloramphenicol, tetracycline or penicillin agar. In some experiments for the recovery of penicillinresistant transductants, the resuspended bacteria were diluted fivefold in BHI broth and incubated for $4 \mathrm{~h}$ at $37^{\circ} \mathrm{C}$ before plating. Streptomycin-resistant transductants were selected after Io-fold dilution in BHI broth and overnight incubation at $37^{\circ} \mathrm{C}$. Selective media contained either $10 \mu \mathrm{g}$ chloramphenicol $\mathrm{ml}^{-1}$, $5 \mu \mathrm{g}$ tetracycline $\mathrm{ml}^{-1}, 50 \mu \mathrm{g}$ streptomycin $\mathrm{ml}^{-1}$, or 0.03 (low-level) or 0.06 (high-level) $\mu \mathrm{g}$ benzylpenicillin $\mathrm{ml}^{-1}$. Low-level penicillin plates also contained $0.2 \%(\mathrm{w} / \mathrm{v})$ starch. Penicillin, streptomycin and chloramphenicol plates included $5 \mathrm{~mm}$-citrate and tetracycline plates, $\mathrm{O} \cdot \mathrm{I} \mathrm{mm}$-citrate. As controls for the recipient strain and for donor phage, duplicate $0.1 \mathrm{ml}$ volumes were plated on to selective media, or, more usually, a transduction experiment was run in parallel from which the recipient was excluded and the recipient was tested separately. Colonies were counted after incubation for 24 to $44 \mathrm{~h}$ at $37^{\circ} \mathrm{C}$. Penicillinase production of colonies was tested on starch-containing media by developing with a penicillin/iodine solution (Dyke, Jevons \& Parker, I966). For studies of the effect of u.v. irradiation on transduction frequency, donor phage preparations $(2.5 \mathrm{ml})$ were irradiated in glass Petri dishes $(9 \mathrm{~cm}$ diam.) at a distance of $23 \mathrm{~cm}$ from a u.v. source (Hanovia with $9.5 \mathrm{~cm}$ of the tube exposed) and agitated every $30 \mathrm{~s}$.

Identification of transductants. For routine identification of transductants, colonies were purified and tested for antibiotic and phage sensitivity. Phage sensitivity was tested using the supernatant phages of strains BSIO and 1833 and the transducing phage preparation of phage 108. In later experiments, sensitivity 
to phage 82 was also tested. In early experiments a proportion of transductants for each character were phage-typed.

A variable number of tetracycline-resistant transductants lost sensitivity to the four phage preparations used for identification, including the transducing phage 108. Many of the transductant colonies on the selective medium appeared lysed. The incidence was not affected by a Io-fold difference in phage input numbers ( 0.09 and 0.9$)$ but could be prevented by selection using BHI agar; on this medium transductant colonies were no longer lysed and had the same phage sensitivity as the recipient ASI5 suggesting that secondary infection and lysogenization by the transducing phage preparation was occurring on the plate. Occasional transductants of this kind were also found among penicillin-, streptomycin- and chloramphenicolresistant transductants. In addition, in some experiments a small number of transductants resistant to any one of the four selected markers showed a reduced sensitivity to the transducing phage 108 and to the supernatant phages of BSIO and I833. A penicillin-resistant transductant of this type released a phage which lysed the recipient strain ASI 5, suggesting that lysogenization of these transductants may have occurred. The donor strain BSIO is lysogenic so that phage(s) other than the transducing phage 108 will be present in phage 108 propagated on BSIO. These transductants were not studied further.

Loss of penicillinase production. The method used was that of Asheshov (1966), except that cultures were grown at 43.5 or $37^{\circ} \mathrm{C}$ for $27 \mathrm{~h}$ before plating on to starch $\mathrm{CY}$ agar. Treated cultures were sufficiently diluted to give 100 to 200 c.f.u. per plate; when penicillinase-negative colonies were required for further study, colonies were replicated to nutrient agar before the starch plate was developed.

Host-controlled modification and restriction. This was studied using phage 82 or the phage in the supernatant of strain 1833. Phage grown on a particular host strain was obtained by picking a single plaque with a Pasteur pipette from a titration plate using the required host strain as the indicator. The plaque was emulsified in I ml nutrient broth and filtered (Millipore, $0.45 \mu \mathrm{m}$ pore size) before further use. The effect of heat on host-controlled modification and restriction was tested by the method of Asheshov \& Jevons (1963) in which the indicator strain was heated for $2 \mathrm{~min}$ at $56^{\circ} \mathrm{C}$.

Efficiency of plating (e.o.p.). This is defined as the titre of phage on a given strain relative to its titre on the recipient strain ASI5. When the e.0.p. was between 0.8 and $I \cdot 0$ it was arbitrarily described as $I \cdot 0$.

\section{RESULTS}

\section{Transduction of resistance}

Independent transfer of $\mathrm{Cm}, \mathrm{Tc}$ and $\mathrm{Sm}$ resistance and Pc resistance due to penicillinase production occurred following selection for a single character (Table I). Without u.v. irradiation of phage, the frequency of streptomycin-resistant transductants was low and was less than $\mathrm{I} \cdot 8 \times 10^{-9}$ transductant colonies per phage input on several occasions. During the period of unselected growth of cultures screened for streptomycin-resistant transductants, the final number of c.f.u. $\mathrm{ml}^{-1}$ increased two- to threefold so that the frequency given per phage input is an overestimate. The number of penicillin-resistant transductant colonies on plates containing $0.03 \mu \mathrm{g}$ penicillin $\mathrm{ml}^{-1}$ varied as much as twofold, but a limited period of unselected growth reduced the variability. However, the results given indicate the actual transduction frequency at $0 \mathrm{~h}$. Numbers on $0.06 \mu \mathrm{g}$ penicillin $\mathrm{ml}^{-1}$ plates were also variable. A small number of penicillinase-negative colonies grew on some of the $0.03 \mu \mathrm{g}$ penicillin $\mathrm{ml}^{-1}$ plates. These colonies differed slightly in appearance from the bla transductant colonies but were more satisfactorily identified by testing for penicillinase production by the starch iodine method. About 20 penicillinase-negative colonies occurred on plates with about I $50 \mathrm{bla}^{+}$colonies.

No cotransduction of resistance was found for any of the four selected markers or for $\mathrm{Hg}^{2+}$ or $\mathrm{Cd}^{2+}$ when $62 \mathrm{Pc}$ (high), I I8 Pc (low), 8I Tc, $77 \mathrm{Cm}$ and $29 \mathrm{Sm}$ transductant colonies were tested.

\section{Phage sensitivity of penicillin-resistant transductants}

Penicillin-resistant transductants ( 76 colonies) selected on $0.06 \mu \mathrm{g}$ penicillin $\mathrm{ml}^{-1}$ plates were compared with the recipient strain ASI 5 for sensitivity to the four phages used for strain identification: 70 showed a I0- to roo-fold reduction in sensitivity to phage 82 and to the supernatant phage of strain 1833 although they were unchanged in sensitivity to the 
Table I. Transduction of resistance in $S$. epidermidis from donor BSIO to recipient ASI 5 by phage 108

$\begin{array}{cccc}\begin{array}{c}\text { Selected } \\ \text { resistance }\end{array} & \begin{array}{c}\text { Concn } \\ \text { for selection } \\ \left(\mu \mathrm{g} \mathrm{m} \mathbf{l}^{-1}\right)\end{array} & \begin{array}{c}\text { Time of } \\ \text { selection } \\ (\mathrm{h})\end{array} & \begin{array}{c}\text { No. of } \\ \text { transductant } \\ \text { colonies per } \\ \text { phage input }\end{array} \\ \text { Cm } & 10 & 0 & 4.3 \times 10^{-5} \\ \text { Tc } & 5 & 0 & 3.5 \times 10^{-6} \\ \text { Sm } & 50 & \text { Approx. } 20 & 4.5 \times 10^{-8} \\ \text { Pc } & 0.03 & 0 & 9.1 \times 10^{-6} \\ \text { Pc } & 0.06 & 0 & 2.1 \times 10^{-7}\end{array}$

* Cm, Chloramphenicol; Tc, tetracycline; Sm, streptomycin; Pc, penicillin.

Table 2. Effect of pretreatment with heat of the restricting strain S. epidermidis AS39 on the efficiency of plating of phage 82

\begin{tabular}{|c|c|c|}
\hline \multirow[b]{2}{*}{$\begin{array}{l}\text { Phage } 82 \text { passed } \\
\text { through strain: }\end{array}$} & \multicolumn{2}{|c|}{$\begin{array}{l}\text { E.o.p.* on As39 after } \\
\text { pretreatment at: }\end{array}$} \\
\hline & $37^{\circ} \mathrm{C}$ & $56{ }^{\circ} \mathrm{C}$ \\
\hline ASI 5 & $\mathrm{I} \cdot 2 \times 10^{-2}$ & $2.2 \times 10^{-1}$ \\
\hline ASI 5 . AS39 & $I \cdot O$ & $I \cdot 0$ \\
\hline ASI 5. AS39. ASI 5 & $7.5 \times 10^{-3}$ & $1.6 \times 10^{-1}$ \\
\hline
\end{tabular}

* E.o.p. on AS39 is defined as the titre on AS39 compared with the titre on ASI5.

transducing phage 108 and the supernatant phage of the donor strain BSIo. Sixteen of the transductants with altered phage sensitivity had either reduced or lost sensitivity to four of the typing phages, A9C, 7I, 48 and I57A (Dean et al., 1973), which lysed ASI5. This altered sensitivity was sufficient for the transductants to be described as different from the recipient strain ASI5. Penicillin-resistant transductants selected on $0.03 \mu \mathrm{g}$ penicillin $\mathrm{ml}^{-1}$ plates did not usually show any change in phage sensitivity when identified routinely. Only I 6 out of I30 colonies tested showed the reduced phage sensitivity which was such a conspicuous feature of Pc transductants selected on the higher concentration of penicillin.

\section{Phage restriction and modification}

Penicillin-resistant transductants with reduced phage sensitivity, whether selected on 0.06 or $0.03 \mu \mathrm{g}$ penicillin $\mathrm{ml}^{-1}$, were 10 - to 100-fold less sensitive to phage 82 than was the recipient ASI 5. Passage of phage 82 through one of these transductants (AS39) produced a phage which gave the same titre on strain AS39 as on ASI5, but this effect was lost after subsequent passage of this phage through a bla- revertant of AS39, or through ASI5, showing that Pc transductants of this type have a restriction (Res) and modification (Mod) system which is linked to the penicillinase marker. Further evidence that a restriction system is operating comes from the effect of pretreatment of the restricting strain at $56^{\circ} \mathrm{C}$ for $2 \mathrm{~min}$ (Asheshov \& Jevons, 1963; Schell \& Glover, 1966) before assay of phage 82, which removed or substantially reduced the lower efficiency of plating on the bla+ $\mathrm{Mod}^{+} \mathrm{Res}^{+}$strain AS39 (Table 2).

Although the donor strain used for phage propagation originated from three singlecolony purification steps, the production of the two classes of bla transductants was confirmed using phage propagated on separate, single-colony cultures of BS Io to establish that the donor strain did not contain two different types of $b l a^{+}$bacteria. Three phage lysates prepared in this way produced similar proportions of transductants on $0.06 \mu \mathrm{g}$ penicillin $\mathrm{ml}^{-1}\left(\mathrm{I} \cdot 8 \times \mathrm{IO}^{-7}\right.$ to $\left.\mathrm{I} \cdot 4 \times \mathrm{IO}^{-6}\right)$ and higher frequencies on $0.03 \mu \mathrm{g} \mathrm{ml}^{-1}\left(3.8 \times \mathrm{IO}^{-5}\right.$ to $\left.5.7 \times \mathrm{IO}^{-5}\right)$. The proportion of transductants with the two types of phage sensitivity was similar for the 
Table 3. Effect of growth temperature on the stability of penicillin resistance in the donor strain BSIO and in penicillin-resistant transductants

\begin{tabular}{|c|c|c|c|}
\hline Strain & $\begin{array}{c}\text { Temp. } \\
\left({ }^{\circ} \mathrm{C}\right)\end{array}$ & $\begin{array}{l}\text { No. of } \\
\text { colonies } \\
\text { tested }\end{array}$ & $\begin{array}{l}\text { No. of } \\
\text { penicillinase-negative } \\
\text { colonies } \dagger\end{array}$ \\
\hline BSIO & $\begin{array}{c}37 \\
43-44\end{array}$ & $\begin{array}{l}3066 \\
4699\end{array}$ & $\begin{array}{l}0(<0.03) \\
0(<0.02)\end{array}$ \\
\hline AsI 5 bla $^{+}$Mod $^{+}$Res $^{+}$ & $\begin{array}{c}37 \\
43-44\end{array}$ & $\begin{array}{l}2843 \\
815^{*}\end{array}$ & $\begin{array}{c}2(<0.07) \\
45^{*}(5.0)\end{array}$ \\
\hline ASI 5 bla $^{+}$ & $43-44$ & 1800 & $0(<0.06)$ \\
\hline
\end{tabular}

three phage preparations. The reduced sensitivity associated with modification and restriction occurred in $\mathrm{I} / \mathrm{10}, 4 / \mathrm{IO}$ and $3 / 10$ transductants selected on $0.03 \mu \mathrm{g} \mathrm{ml}^{-1}$ plates and in $9 / 9,9 / 10$ and $10 / 10$ transductants from the $0.06 \mu \mathrm{g}$ penicillin $\mathrm{ml}^{-1}$ selection .

\section{Stability of penicillinase production}

The penicillinase character in the donor strain Bsıo was very stable; screening of more than $10^{3}$ bacteria after growth at $37^{\circ} \mathrm{C}$ and on two occasions at 43 to $44{ }^{\circ} \mathrm{C}$ failed to produce any bla colonies (Table 3). A bla ${ }^{+}$transductant unaltered in phage sensitivity was similarly stable after growth at the higher temperature but two $\mathrm{bla}^{+} \mathrm{Mod}^{+} \mathrm{Res}^{+}$transductants tested were unstable in pencillinase production. In one strain (Table 3) small numbers of bla cells were recovered at $37^{\circ} \mathrm{C}$, but much larger numbers after growth at $43.5^{\circ} \mathrm{C}$ (Table 3). Cultures were usually derived from six colonies, but for the $b l a^{+} \mathrm{Mod}^{+} \mathrm{Res}^{+}$strain at $43.5{ }^{\circ} \mathrm{C}$ the value was the average for a series of eight separate cultures each derived from a single colony and tested on one occasion. Loss values varied from 3.7 to $6.6 \%$ of colonies plated. Occasionally 20 to $30 \%$ of the colonies plated had lost the ability to produce penicillinase. The difference in the proportion of penicillinase-negative colonies was not due to faster growth of $b l a^{-}$compared to $b a^{+}$transductants. The growth rates at $43.5{ }^{\circ} \mathrm{C}$ of a $\mathrm{bla}^{+}$ $\mathrm{Mod}^{+} \mathrm{Res}^{+}$transductant and of a non-penicillinase-producing isolate derived from it were very similar, both having an average generation time of $\mathrm{I} \mathrm{h} 24 \mathrm{~min}$.

\section{Ultraviolet irradiation of transducing phage}

Frequencies of transduction of $\mathrm{Cm}$ and $\mathrm{Tc}$ resistance were reduced by u.v. irradiation of the transducing phage preparation (Fig. I) giving the pattern expected of plasmid genes. The initial rate at which the ability to transduce $\mathrm{Cm}$ resistance was reduced was slow but subsequently transduction frequencies for both $\mathrm{Cm}$ and $\mathrm{Tc}$ fell at similar rates. The ability to transduce $\mathrm{Sm}$ resistance showed the characteristic effect on a chromosomal marker with an increased transduction frequency at low u.v. doses reaching a maximum at 3 to 4 min. The effect on the transduction frequency of $b l a^{+}$produced the result expected of a plasmid gene. It had been found that the approximately twofold difference in the number of $b l a^{+}$ colonies on individual plates was reduced if a period of $4 \mathrm{~h}$ growth in nutrient broth was allowed before the $b a^{+}$transductants were selected on $0.03 \mu \mathrm{g}$ penicillin $\mathrm{ml}^{-1}$ suggesting that phenotypic expression lag was occurring in a proportion of transductants. As the relative position of the readings on the curve was more important than the actual transduction rate, this period of unselected growth was used in determining the values shown in Fig. I for $b^{+} a^{+}$transduction, with the result that the frequency per phage input at o min u.v. dose was different from the value shown in Table I when selection followed directly after the transduction period. Bacterial counts of each culture at $4 \mathrm{~h}$ were similar and the transduction frequency expressed per number of bacteria in the culture produced a similar curve to 


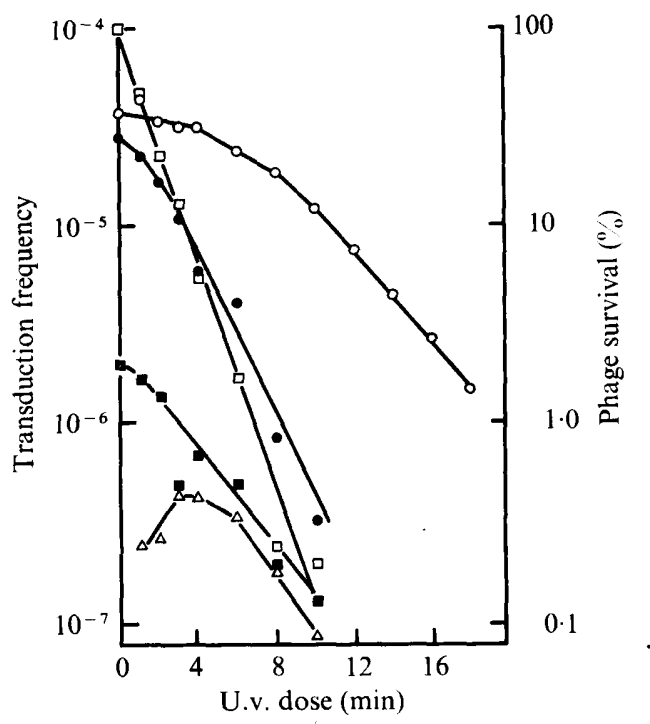

Fig. I. Frequency of transduction of resistance markers as a function of u.v. dose given to the transducing phage, I08. Recipient, ASI5; donor, BSIO; input ratios, 0.1 to 0.4 . Penicillin transductants were grown for $4 \mathrm{~h}$ in nutrient broth before selection. Phage inactivation ( $\square$ ); frequency of transduction of resistance to chloramphenicol $(O)$, penicillin $(O)$, tetracycline $(\square)$ and streptomycin $(\triangle)$.

that shown in Fig. I. Although the number of transductant colonies following selection on $0.06 \mu \mathrm{g}$ penicillin $\mathrm{ml}^{-1}$ was rather low, it was probable that a similar reduction in numbers also occurred at this concentration. The frequency of transduction in one experiment was reduced from $3.1 \times 10^{-8}$ transductant colonies per phage at 0 min to $9.3 \times 10^{-9}$ after 4 min u.v. irradiation of phage.

\section{DISCUSSION}

Our results confirm those of Rosendorf \& Kayser (1974) on the frequency of transduction of $\mathrm{Tc}, \mathrm{Cm}$ and $\mathrm{Sm}$ resistance and the effect of u.v. irradiation of the transducing phage on the transduction kinetics, and those of Minshew \& Rosenblum (I973) for Tc resistance. There was no increase in the frequency of transduction of $\mathrm{Cm}$ or $\mathrm{Tc}$ markers even at low doses indicating that both characters are plasmid mediated. Nazar et al. (1977) demonstrated a high frequency of transduction (about $10^{-2}$ ) of $b l a^{+}$using one phage and a particular strain of $S$. epidermidis $\mathrm{BV}$ as donor; the recipient was a bla', mannitol- and ribosenegative variant derived from the donor in one step. $b l a^{+}$transductants also received the mannitol and ribose markers. When other phages were used, the frequency was about $\mathrm{I} \times \mathrm{IO}^{-5}$ to $5 \times 10^{-5}$ which is nearer to the frequency obtained in this study. No kinetics of the effect of u.v. irradiation were reported, but at the dose of $5 \mathrm{~min}$ employed very little change in transduction frequency was found. The evidence suggested a plasmid location for the bla ${ }^{+}$character (Nazar et al., 1977). Unlike sII strains of $S$. epidermidis, BV strains ferment mannitol and are not susceptible to the phages which lyse sII strains (Schaefler, 1971). The strains tested by Rosendorf \& Kayser (1974) which failed to show penicillinase transfer were similar to our strains, being multiply drug resistant and belonging to the sII group of S. epidermidis. Successful transduction of Pc depended on using low levels of benzylpenicillin for selection of transductants. The minimal inhibitory concentration (m.i.c.) of our strains was not tested, but a fairly wide range of m.i.c. values with benzylpenicillin has been reported by Pulverer, Damen \& Neugebauer (1972) including values of $<0.02 \mu \mathrm{g}$ $\mathrm{ml}^{-1}$ for oxacillin-sensitive strains. Selection on $0.03 \mu \mathrm{g}$ penicillin $\mathrm{ml}^{-1}$ gave the largest 
number of penicillin transductants which could be clearly distinguished from bla recipient colonies. Recipient colonies grew in fairly small numbers at this concentration although there was no growth when recipients alone were plated. As the donor BS Io was resistant to methicillin it had not been possible to predict the amount of penicillin required for selection by a reconstruction experiment to recover small numbers of donor bacteria in a sensitive recipient population. Although as little as a twofold increase in the concentration of penicillin to $0.06 \mu \mathrm{g} \mathrm{ml}^{-1}$ caused a drastic reduction in the recovery of transductants, the number of transductants recovered at the different concentration was consistent.

The rate of reduction in transduction frequency with u.v. dose was much more rapid for Pc than for $\mathrm{Cm}$ or Tc markers but was closer to the rate at which plaquing capacity of the transducing phage 108 was reduced. This could be taken to suggest that the penicillinase plasmid is larger that the $\mathrm{Cm}$ or Tc markers which would be consistent with the relative sizes established for these plasmids in S. aureus (see Lacey, 1975). Rosendorf \& Kayser (1974) have shown that the $\mathrm{Cm}$ and Tc plasmids in $S$. epidermidis are of a similar size to those in $S$. aureus having a molecular weight of $2.6 \times 10^{6}$ to $2.8 \times 10^{6}$.

A number of $b a^{+}$transductants, with the proportion depending on the concentration of penicillin used for selection, showed restriction and modification of certain phages which resulted in a change in phage type. Verhoef, van Boven \& Holtrigter (I972) identified three groups of sII $S$. epidermidis whose phage patterns were mainly determined by host-controlled modification and restriction systems. Linkage between bla and restriction and modification was shown by Schaefler (1972) in the group of physiologically distinct strains (BV) in which bla was unstable.

Instability of bla in this study was only associated with transductants which were also $\mathrm{Res}^{+}$and $\mathrm{Mod}^{+}$, while the donor strain and bla transductants with unaltered phage sensitivity showed a high level of stability. Both stable and unstable Pc resistance occurs in S. epidermidis (Baldwin, Strickland \& Cox, 1969) and resistance was stable in the strains which failed to transfer Pc by transduction (Rosendorf \& Kayser, 1974).

We thank Dr E. H. Asheshov for advice and encouragement, Ms J. M. Cameron for excellent technical assistance and Dr L. S. Nakhla and Mr M. A. Curtis for phage typing.

\section{REFERENCES}

ADAMs, M. H. (1959). Bacteriophages. New York, London and Sydney: Wiley-Interscience.

AsHeshov, E. H. (1966). Loss of antibiotic resistance in Staphylococcus aureus resulting from growth at high temperature. Journal of General Microbiology 42, 403-410.

Asheshov, E. H. \& Jevons, M. P. (1963). The effect of heat on the ability of a host strain to support the growth of a Staphylococcus phage. Journal of General Microbiology 3r, 97-107.

BAIRD-PARKER, A. C. (1963). A classification of micrococci and staphylococci based on physiological and biochemical tests. Journal of General Microbiology 30, 409-427.

BAIRD-PARKER, A. C. (I966). In Identification Methods for Microbiologists, pp. 59-64. Edited by B. M. Gibbs and F. A. Skinner. London and New York: Academic Press.

BAIRD-PARKer, A. C. (I974). The basis for the present classification of staphylococci and micrococci. Annals of the New York Academy of Sciences 236, 7-13.

Baldwin, J. N., Strickland, R. H. \& Cox, M. F. (1969). Some properties of the betalactamase genes in Staphylococcus epidermidis. Applied Microbiology 18, 628-630.

Chalmers, A. (1972). A modification of the oxidation/fermentation test for the classification of Micrococcaceae. Medical Laboratory Technology 29, 379-384.

Corse, J. \& Williams, R. E. O. (I968). Antibiotic resistance of coagulase-negative staphylococci and micrococci. Journal of Clinical Pathology 21, 722-728.

Dean, B. A., Williams, R. E. O., Hall, F. \& CORSE, J. (1973). Phage typing of coagulase-negative staphylococci and micrococci. Journal of Hygiene, Cambridge 71, 26I-270.

Dyke, K. G. H., Jevons, M. P. \& Parker, M. T. (1966). Penicillinase production and intrinsic resistance to penicillins in Staphylococcus aureus. Lancet i, 835-838.

LACEY, R. W. (1975). Antibiotic resistance plasmids of Staphylococcus aureus and their clinical importance. Bacteriological Reviews 39, I32.

Minshew, B. H. \& Rosenblum, E. D. (1972). Transduction of tetracycline resistance in Staphy- 
lococcus epidermidis. Antimicrobial Agents and Chemotherapy 1, 508-5I I.

Minshew, B. H. \& Rosenblum, E. D. (1973). Plasmid for tetracycline resistance in Staphylococcus epidermidis. Antimicrobial Agents and Chemotherapy 3, 568-574.

Nazar, K., Heczko, P. B. \& Pulverer, G. (1977). Transduction of penicillin resistance together with ability to ferment mannitol and ribose in Staphylococcus epidermidis. Journal of General Microbiology 99, 449-452.

Noble, W. C. (I969). Skin carriage of the Micrococcaceae. Journal of Clinical Pathology 22, 249253.

Novick, R. P. (1963). Analysis by transduction of mutations affecting penicillinase formation in Staphylococcus aureus. Journal of General Microbiology 33, I 2 I-1 36.

Poston, S. M. (I966). Cellular location of the genes controlling penicillinase production and resistance to streptomycin and tetracycline in a strain of Staphylococcus aureus. Nature, London 210, 802804.

Pulverer, G., Damen, G. \& Neugebauer, M. (1972). Antibiotic resistance of Staphylococcus albus. Medical Microbiology and Immunology $\mathbf{5 8}, 32-43$.
RoSENDORF, L. 1. \& KAYSER, F. H. (I974). Transduction and plasmid deoxyribonucleic acid analysis in a multiply antibiotic-resistant strain of Staphylococcus epidermidis. Journal of Bacteriology 120, 679-686.

SCHAEFLER, S. (1971). Staphylococcus epidermidis BV: antibiotic resistance patterns, physiological characteristics and bacteriophage susceptibility. Applied Microbiology 22, 693-699.

SCHAEFler, S. (1972). Polyfunctional penicillinase plasmid in Staphylococcus epidermidis: bacteriophage restriction and modification mutants. Journal of Bacteriology 112, 697-706.

Schell, J. \& Glover, S. W. (I966). The effect of heat on host-controlled restriction of phage $\lambda$ in Escherichia coli $\mathbf{k}(\mathrm{PI})$. Journal of General Microbiology 45, 6I-72.

Verhoef, J., van Boven, C. P. A. \& Holtritger, B. (I972). Host-controlled modification and restriction of phages in coagulase-negative staphylococci. Journal of General Microbiology 71, 23 I-239.

YU, L. \& BALDWIN, J. N. (197I). Intraspecific transduction in Staphylococcus epidermidis and interspecific transduction between Staphylococcus aureus and Staphylococcus epidermidis. Canadian Journal of Microbiology 17, 767-773. 